\title{
Acetylcholine Receptor Modulation Antibody to Acetylcholine Receptor Antibody Ratio Measurement
}

National Cancer Institute

\section{Source}

National Cancer Institute. Acetylcholine Receptor Modulation Antibody to Acetylcholine

Receptor Antibody Ratio Measurement. NCI Thesaurus. Code C147297.

The determination of the ratio of acetylcholine receptor modulation antibody compared to acetylcholine receptor antibody present in a sample. The measurement may be expressed as a ratio or percentage. 